\title{
A Fuzzy-Grey Multicriteria Decision Making Approach for Green Supplier Selection in Low-Carbon Supply Chain
}

\author{
Qinghua Pang, Tiantian Yang, Mingzhen Li, and Yi Shen \\ School of Business Administration, Hohai University, Changzhou 213022, China \\ Correspondence should be addressed to Qinghua Pang; pangqh77@126.com
}

Received 25 April 2017; Revised 30 June 2017; Accepted 19 July 2017; Published 17 August 2017

Academic Editor: Love Ekenberg

Copyright (C) 2017 Qinghua Pang et al. This is an open access article distributed under the Creative Commons Attribution License, which permits unrestricted use, distribution, and reproduction in any medium, provided the original work is properly cited.

\begin{abstract}
Due to the increasing awareness of global warming and environmental protection, many practitioners and researchers have paid much attention to the low-carbon supply chain management in recent years. Green supplier selection is one of the most critical activities in the low-carbon supply chain management, so it is important to establish the comprehensive criteria and develop a method for green supplier selection in low-carbon supply chain. The paper proposes a fuzz-grey multicriteria decision making approach to deal with these problems. First, the paper establishes 4 main criteria and 22 subcriteria for green supplier selection. Then, a method integrating fuzzy set theory and grey relational analysis is proposed. It uses the membership function of normal distribution to compare each supplier and uses grey relation analysis to calculate the weight of each criterion and improves fuzzy comprehensive evaluation. The proposed method can make the localization of individual green supplier more objectively and more accurately in the same trade. Finally, a case study in the steel industry is presented to demonstrate the effectiveness of the proposed approach.
\end{abstract}

\section{Introduction}

Low-carbon supply chain has been a popular research topic in recent years due to increasing environment stress on economy and global warming, which are mainly caused by carbon emissions. Trucost [1] conducted an interesting survey which shows that only 19 percent of the total carbon emissions in the supply chain is generated from direct operational activities of the company and the rest of the 81 percent emissions are generated from other indirect activities, such as emissions from first-tier supplier. Many countries have launched a series of measures to reduce carbon emissions from their domestic enterprises. To cope with pressure from governments and from the market, it is a critical factor for the enterprises to select their suitable green suppliers who have affinity with low-carbon ability, while green supplier selection is considered as a complex multicriteria decision making (MCDM) problem since various and discordant criteria should be taken into account and assessed during the process $[2,3]$. Therefore it is critically important to study green supplier selection in low-carbon supply chain. Through research, it is possible not only to improve the efficiency and cut the costs of the supply chain but also to achieve carbon emissions reduction and improve environmental performance of the supply chain.

Although many studies exist on the topic of supplier selection, the research on the green supplier selection in lowcarbon supply chain is fairly rare [4-6]. Most of them focus on economic supplier selection and they do not consider environmental and social aspects. It is inappropriate for enterprises to select green supplier in low-carbon economy. Moreover, low-carbon supply chain management has been considered as an integration and realization of an enterprise's economic, environmental, and social objectives to improve its performance. When the enterprise selects its green supplier, it needs to pay special attention to proactively build lowcarbon principles into its supply chain management, which is one of the most critical factors for the success of lowcarbon supply chain. However, many studies have ignored this point. In addition, although extensive MCDM methods have been proposed for supplier selection, there are still some problems that need to be addressed. One is that they need to nondimensionalize the criteria, which will bring about a lot of calculating work, especially when there are many qualitative criteria. Another is how to calculate the weight 
of each criterion. Different understanding of green supplier selection decides which method should be used to calculate the weight of each criterion. In fact, people's understanding of the weights of criteria for green supplier selection is in a grey state [7]. So grey relational analysis maybe is the most suitable method to calculate the weights of criteria.

Based on the above discussion, the objective of this research is to develop an integrated approach for green supplier selection in low-carbon supply chain. Considering the economic, environmental, and social aspects in the low-carbon supply chain condition, we establish 4 main criteria and 22 subcriteria for green supplier selection. An integrated method based on fuzzy set theory and grey relational analysis for green supplier selection is proposed. The proposed methodology integrates the merits of fuzzy set theory and grey relational analysis. Fuzzy set theory is used for the nature of unquantifiable and incomplete information, and judgments are fuzzy in green supplier selection. Grey relational analysis is used to calculate the weight of each criterion due to the grey state of people's understanding of the weights of criteria for green supplier selection. The strength of the proposed method is that, despite the vagueness of experts' opinions in the selection process, the model is easy to apply. Moreover, with the proposed method, enterprises can help their suppliers to improve sustainability for better management of low-carbon supply chain operations. A real case in steel industry is also studied to verify the applicability of the proposed criteria and methods for green supplier selection in low-carbon supply chain.

The main contribution of this paper is developing a fuzzy-grey MCDM approach for green supplier selection in low-carbon supply chain. The paper establishes the main criteria and subcriteria for green supplier selection after considering enterprises' requirements in low-carbon supply chain management, which can help enterprise to identify the potential areas where green suppliers need to improve. The proposed method provides a mechanism of integrating the economic, social, and environmental criteria to fully reflect the requirements of low-carbon supply chain, which helps to avoid potential risk of selecting the wrong suppliers. In the proposed method, it also introduces a membership function of normal distribution, which is a dimensionless method. To the best of our knowledge, no previous studies have investigated the subject of green supplier selection with this kind of integrated method. The proposed method has been successfully implemented in a case company to select its best green supplier and analyze its most appropriate alternative green supplier. This research's results will improve the managers' view on the nature of green supplier selection criteria. Besides, the proposed method can be widely used as a structural model for green supplier selection.

The rest of this paper is organized as follows: Section 2 presents a brief review of the low-carbon supply chain, selection criteria, and MCDM methods used for green supplier selection. Section 3 establishes the criteria for green supplier selection in low-carbon supply chain. Section 4 proposes a method integrating fuzzy set theory and grey relational analysis, in which a membership function of distribution also is introduced. Section 5 provides a real case study concerning green supplier selection example to demonstrate the applicability and validity of the proposed criteria and method. Conclusions and directions for future research in the area are presented in Section 6.

\section{Literature Review}

Supplier selection has received considerable attention for its significant effect towards successful supply chain management. A considerable number of literature reviews are accomplished by various authors such as Govindan et al. [8], Igarashi et al. [9], Ho et al. [10], de Boer et al. [11], Wu and Barnes [12], and Chai et al. [13]. In this section, we classify the literatures related to our work into three categories. The first category includes the works on low-carbon supply chain. The second category includes the studies with a focus on the criteria for green supplier selection. The third category explores the literatures on the method for green supplier selection. Here we review some recent representative works in the literature as follows.

2.1. Low-Carbon Supply Chain. Climate change is global in scope and it is necessary to reduce carbon emissions at the global level. Since carbon emissions are omitted across the entire supply chain, the focus of a firm's environmental management to reduce carbon emissions has shifted from individual firms towards the entire supply chain. The objective of low-carbon supply chain is to reduce carbon emissions across the entire supply chain.

Shaw et al. [14] presented an integrated approach for selecting the appropriate supplier in the supply chain, addressing the carbon emission issue, and using fuzzy-AHP and fuzzy multiobjective linear programming; further they [15] proposed a chance constrained based on green supply chain network design model addressing carbon emissions and carbon trading issues. Nakajima et al. [16] identified the requirements and challenges of promoting a low-carbon supply chain caused by the introduction of material flow cost accounting, and the study showed that setting environmental indicators as performance evaluation criteria of a company's purchasing department is an important step in the lowcarbon supply chain. Wang et al. [17] focused on a dyadic supply chain with a manufacturer and a retailer to develop a game model for studying the issues of carbon emission reduction within the retailer dominant and the power balanced cases under the low-carbon environment. Zhou et al. [18] studied a low-carbon supply chain channel with one manufacturer and one retailer and showed how to optimize the lowcarbon supply chain management decision and improve the supply chain performance through contract design. Mao et al. [19] analyzed the relationship between internal lowcarbon integration and external low-carbon integration and firm performance by researching 12 business departments of machinery, electronics, and transportation components industries in China based on the natural resource-based view.

These literatures show low-carbon supply chain has become a popular research topic. Due to the characteristics of carbon emissions, it is important for the enterprises to form a low-carbon supply chain to reduce carbon emissions, 
in which selecting suitable green supplier is one of the key factors. The criteria and methods for green supplier selection are two extremely important aspects, which determine whether the enterprise can achieve the goal of low-carbon supply chain management or not to a certain extent.

2.2. Criteria for Green Supplier Selection. Many authors have stressed the importance of selecting suitable (qualitative and quantitative) criteria in the green supplier selection process. The traditional criteria for supplier selection have solely considered economic aspects for many years [20,21]. While in low-carbon supply chain management, enterprises must add the environmental or ecological and social factors to the traditional supplier selection criteria such as quality, cost, delivery, and service to remain in the low-carbon supply chain [22].

Lee et al. [23] proposed quality, technology capability, pollution control, green products, and green competencies for green supplier selection in the high-tech industry. Tseng [24] proposed 16 main green criteria, such as green technology capabilities, green purchasing capabilities, green design, and green certifications. Hsu et al. [25] established 13 criteria of carbon management with three dimensions (planning, implementation, and management). Gurel et al. [26] proposed 8 main criteria, such as cost, delivery, quality, service, strategic alliance, and pollution control, and 30 subcriteria which consist of green and also nongreen criteria. Dobos and Vörösmarty [27] divided the criteria into two manners: the managerial and the green factors and used DEA-type composite criteria for green supplier selection. Awasthi et al. [28] proposed 12 criteria including use of environmental friendly technology, use of environmental friendly material, partnership with green organization, green market share, management commitment, adherence to environmental policies, green $\mathrm{R} \& \mathrm{D}$ projects, and staff training. Masoud et al. [29] proposed ten criteria for green supplier selection, such as use of green materials, air emission level, waste level, and green design capability, and used a fuzzy analytical network process to weight the extracted measures and determine their importance level.

Most of the above literatures focus on economic supplier selection, while neglecting environmental and social aspects. It is inappropriate in the era of low-carbon economy, especially in low-carbon supply chain condition. The criteria determine what we should consider for green supplier selection, so they should adhere to scientific, dynamic, comprehensive, and oriented principles. That is to say, the criteria should include economic, environmental, and social aspects, which can meet the enterprise's requirements for green supplier selection in low-carbon supply chain.

\subsection{Methods for Green Supplier Selection. Extensive MCDM} methods have been proposed for supplier selection, like the analytic hierarchy process (AHP), analytic network process (ANP), data envelopment analysis (DEA), fuzzy set theory, genetic algorithm (GA), mathematical programming, technique order preference by similarity to ideal solution (TOPSIS), and so forth and their hybrids $[9,10,30,31]$.
Amindoust et al. [32] proposed a new ranking method on the basis of fuzzy inference system (FIS) for sustainable supplier selection problem. Darabi and Heydari [33] proposed an interval-valued hesitant fuzzy ranking method to rank the green suppliers candidates under conflicted criteria. Kuo et al. [34] developed a green supplier selection model which integrates artificial neural network (ANN) and DEA and ANP. Kannan et al. [5] presented an integrated approach, of fuzzy multiattribute utility theory and multiobjective programming, for rating and selecting the best green suppliers according to economic and environmental criteria and then allocating the optimum order quantities among them. Karsak and Dursun [35] proposed a fuzzy multicriteria group decision making approach that makes use of quality function deployment and fusion of fuzzy information, and 2-tuple linguistic representation model was developed for supplier selection. Yamada et al. [36] proposed a low-carbon and economic supplier selection with an estimation method of the carbon emissions and conducted a material based analysis for both of the procurement costs minimization and the carbon emissions reduction. Yazdani et al. [37] proposed an integrated approach for green supplier selection by considering various environmental performance requirements and criteria. Hamdan and Cheaitou [6] integrated three methods, fuzzy set theory, TOPSIS, and AHP, to solve a multiperiod green supplier selection and order allocation problem. Banaeian et al. [38] compared the application of three fuzzy MCDM methods, fuzzy set theory with TOPSIS, VIKOR, and GRA in an actual case study.

These methods provide a good research basis for this paper. Due to the fuzziness of judgment, fuzzy set theory is always used in supplier selection, such as literatures [6, $33,35]$, while fuzzy set theory needs to nondimensionalize the criteria, which will bring much calculating work. In particular, when there are many qualitative criteria, it is difficult to compare or quantify them. Moreover, the weights of criteria will largely decide the result of supplier selection. In fact, the managers and practitioners are in a grey state when they calculate the weights of criteria according to grey theory. So grey relational analysis is more suitable to calculate the weights than other methods.

From the above literature review, although these proposed criteria and methods have brought great insights to supplier selection, some problems also need to be discussed. The criteria for green supplier selection should include economic, environmental, and social aspects, meeting with the requirements of enterprise in low-carbon supply chain. Due to the nature of unquantifiable and incomplete information, we can use fuzzy set theory to select green supplier. The membership function of normal distribution is introduced in this paper, which does not need to nondimensionalize the criteria and can deal with the qualitative criteria. In addition, because people's understanding of the weights of criteria for green supplier selection is in a grey state, we use grey relational analysis to calculate the weights of criteria. Therefore, we propose a fuzzy-grey multicriteria decision making approach for green supplier selection in low-carbon supply chain. 
TABLE 1: Criteria for green supplier selection in low-carbon supply chain.

\begin{tabular}{|c|c|c|}
\hline & Main criteria & Subcriteria \\
\hline \multirow{22}{*}{$\begin{array}{l}\text { Green supplier selection in } \\
\text { low-carbon supply chain }\end{array}$} & \multirow{6}{*}{$C_{1}$ : enterprise low-carbon qualification } & $C_{11}$ : enterprise scale \\
\hline & & $C_{12}:$ profitability \\
\hline & & $C_{13}:$ debt level \\
\hline & & $C_{14}$ : low-carbon development potential \\
\hline & & $C_{15}: \mathrm{R} \& \mathrm{D}$ innovation \\
\hline & & $C_{16}:$ enterprise reputation \\
\hline & \multirow{5}{*}{$C_{2}$ : low-carbon production and service } & $C_{17}:$ desire of low-carbon cooperation \\
\hline & & $C_{21}:$ quality \\
\hline & & $C_{22}:$ price \\
\hline & & $C_{23}:$ service \\
\hline & & $C_{24}:$ guarantee and compensation \\
\hline & \multirow{4}{*}{$C_{3}$ : low-carbon business operation } & $C_{31}$ : low-carbon production flexibility \\
\hline & & $C_{32}:$ supply capacity \\
\hline & & $C_{33}:$ low-carbon informatization level \\
\hline & & $C_{34}:$ transportation cost \\
\hline & \multirow{7}{*}{$C_{4}$ : low-carbon innovation } & $C_{35}$ : low-carbon strategic compatibility \\
\hline & & $C_{41}:$ low-carbon image \\
\hline & & $C_{42}:$ low-carbon investment \\
\hline & & $C_{43}:$ energy consumption intensity \\
\hline & & $C_{44}:$ low-carbon energy utilization \\
\hline & & $C_{45}$ : green and low-carbon certifications \\
\hline & & $C_{46}:$ low-carbon technology capabilities \\
\hline
\end{tabular}

\section{Proposed Criteria}

According to these reviews and the identified criteria mentioned above, especially with the help of the managers and practitioners in low-carbon supply chain management, we establish 4 main criteria (enterprise low-carbon qualification, low-carbon production and service, low-carbon business operation, and low-carbon innovation) and 22 subcriteria (e.g., low-carbon image and green and low-carbon certifications) for green supplier selection. See Table 1.

3.1. Enterprise Low-Carbon Qualification $C_{1}$. In the complex and changing market environment, if enterprises want to maintain the long-term stability of low-carbon supply chain competition, they should choose those suppliers who have advanced management and good prospects for development in supply chain, thus providing a reliable protection for low-carbon investment and transformation. Finally, they also need to consider the business desire and credibility of cooperation to reduce carbon emissions, which is a prerequisite to establish low-carbon strategic cooperation between enterprise and its supplier.

We can measure enterprise low-carbon qualification from these aspects: the current business status of the enterprise and low-carbon ability for future development and cooperation. The current business status of the enterprise includes enterprise scale, profitability, and debt level. The low-carbon ability for future development includes low-carbon development potential and R\&D innovation. The low-carbon cooperation ability includes enterprise reputation and desire of lowcarbon cooperation.

3.2. Low-Carbon Production and Service $C_{2}$. On one hand, the competitiveness of low-carbon supply chain depends on rapid response to the market, providing customers with high quality and inexpensive products or service to meet their requirements and expectations, which is the same as the traditional supply chain. On the other hand, it also needs to improve service quality and user experience, strengthen aftersales service support, consolidate supply chain cooperation to reduce unnecessary consumption of all aspects, and control carbon emissions. We can measure low-carbon production and service from four aspects: quality, price service, guarantee, and compensation.

3.3. Low-Carbon Business Operation $C_{3}$. High level of lowcarbon supply chain business operation is not only the basis to achieve customers value goal but also the guarantee to reduce carbon emissions which can be reflected by the low-carbon production planning, low-carbon information sharing, cost control, and so forth in the supply chain management. Therefore, green supplier selection in low-carbon supply chain should focus on supplier's flexibility, efficiency, information, and other aspects of performance.

Transportation is one of the important energy consumption methods in the low-carbon supply chain business operation. Under the same condition, the enterprise should choose the supplier that has the lower transportation cost 
for the purpose of low-carbon transportation. In addition, the supplier's strategic compatibility should also be taken into account. Because the strategic objectives indicate the future development of the enterprise, the conflict of strategic objectives will lead to the failure of carbon reduction cooperation. Here, we use low-carbon production flexibility, transportation, strategic compatibility, and so forth to measure the supplier's low-carbon business operation.

3.4. Low-Carbon Innovation $C_{4}$. Low-carbon innovation is used to evaluate whether the green supplier meets the requirements of the low-carbon supply chain. It should be able to guide and promote the alternative suppliers to pay more attention to environmental protection and carbon emissions reduction, make low-carbon strategy planning, and actively develop and use low-carbon technology to control business processes in energy consumption and pollution. The supplier should integrate the low-carbon concept into the daily operation and achieve good low-carbon performance. This main criterion includes 6 subcriteria, such as low-carbon image and green and low-carbon certifications.

\section{Methodology}

This study integrates fuzzy set theory and grey relational analysis to solve the problem of green supplier selection in low-carbon supply chain. Grey relational analysis is used to calculate the weights of green supplier selection criteria, and fuzzy theory is used to evaluate and rank the alternative green suppliers according to the selected criteria. Also, a membership function of normal distribution is introduced to determine the membership degree of each selected criterion. The main steps and the detailed descriptions are depicted as follows.

4.1. Identify Green Supplier Selection Criteria. The first step involves identification of the main criteria and subcriteria for green supplier selection. In Section 3, 4 main criteria and 22 subcriteria (Table 1) have been compiled through relevant literature and input from the managers and practitioners in low-carbon supply chain management. Further, these identified criteria have been categorized into 4 dimensions of low-carbon supply chain with the help of brainstorming sessions with experts. Finally, a hierarchical structural is framed with the criteria and alternative green suppliers.

According to the main criteria and subcriteria shown in Table 1, 4 criteria sets can be established: $C=\left\{C_{1}, C_{2}\right.$, $\left.C_{3}, C_{4}\right\}, C_{1}=\left\{C_{11}, C_{12}, C_{13}, C_{14}, C_{15}, C_{16}, C_{17}\right\}, C_{2}=\left\{C_{21}\right.$, $\left.C_{22}, C_{23}, C_{24}\right\}, C_{3}=\left\{C_{31}, C_{32}, C_{33}, C_{34}, C_{35}\right\}$, and $C_{4}=\left\{C_{41}\right.$, $\left.\mathrm{C}_{42}, \mathrm{C}_{43}, \mathrm{C}_{44}, \mathrm{C}_{45}, \mathrm{C}_{46}\right\}$.

4.2. Establish Evaluation Grade Set. The evaluation grade set is the set of the criteria's evaluation results and indicated by $V: V=\left(v_{1}, v_{2}, \ldots, v_{m}\right)$. Here $v_{i}(1 \leq i \leq m)$ means the $i_{\text {th }}$ evaluation grade and $m$ means the number of total evaluation grades. In this paper, the number of evaluation grades is 4 ; namely, $m=4 ; V=\left(v_{1}, v_{2}, v_{3}, v_{4}\right)=$ (excellet, good, medium, poor).
4.3. Establish Membership Function of Normal Distribution. Here, we introduce a membership function of normal distribution to calculate the membership degree of each criterion. Usually, it needs to nondimensionalize the criteria in the traditional fuzzy method, which will bring about a lot of calculating work, especially when there are many criteria. However we do not need to nondimensionalize the criteria when using membership function of normal distribution. In addition, it is easier for us to find the problems in green supplier selection when we use membership function of normal distribution compared to traditional fuzzy method.

For a certain criterion, the evaluation value is different among different suppliers, while the evaluation value $x_{i}$ obeys the normal distribution as the number $n$ of suppliers increases. For a criterion of $n$ alternative suppliers, suppose $\bar{x}$ and $s$ are the mean value and standard deviation, respectively, and then we can get

$$
z_{i}=\frac{\left(x_{i}-\bar{x}\right)}{s} \sim N(0,1) \quad\left(-\infty<z_{i}<+\infty\right) .
$$

Namely, $z_{i}$ obeys the standard normal distribution in which the expected value is 0 and the standard deviation is 1. For example, in terms of $C_{1}$ (enterprise low-carbon qualification), suppose $\bar{x}=60, s=5$, and $x_{i}=70$ for the $i_{\text {th }}$ supplier, and then $z_{i}=2$ according to formula (1). From normal distribution table, we can get $P\left(z_{i}<2\right)=0.977$, which means the evaluation value of $C_{1}$ of $97.7 \%$ of suppliers is less than the evaluation value of $C_{1}$ of the $i_{\text {th }}$ supplier within $n$ suppliers. So we can use 0.977 as the membership degree of $C_{1}$ of the $i_{\text {th }}$ supplier. In order to simplify the problem, the value of $z_{i}$ is limited in $(-3.1,3.1)$, and then the membership degree belongs to $(0.001,0.999)$. So the membership function of normal distribution can be described as

$$
A(x)= \begin{cases}0 & x \in(-\infty,-3.1] \\ \frac{1}{\sqrt{2 \pi} \int_{-\infty}^{x} e^{-x^{2} / 2} d x} & x \in(-3.1,3.1) \\ 1 & x \in[3.1,+\infty) .\end{cases}
$$

4.4. Construct Fuzzy Judgment Matrix. Suppose there are $q$ experts who evaluate the criteria and the weight of $q$ experts is the same. We can use the mean value of $q$ experts' evaluating values as the evaluation values of the criteria. $R^{\prime}$ denotes the fuzzy relationship between the criteria set $C$ and its evaluation grade set $V$. Here

$$
R^{\prime}=\left[\begin{array}{cccc}
r_{11}^{k} & r_{12}^{k} & \cdots & r_{1 m}^{k} \\
r_{21}^{k} & r_{22}^{k} & \cdots & r_{2 m}^{k} \\
\vdots & \vdots & \vdots & \vdots \\
r_{n 1}^{k} & r_{n 2}^{k} & \cdots & r_{n m}^{k}
\end{array}\right],
$$

and $r_{i j}^{k}$ means the evaluation value of $j_{\text {th }}$ evaluation grade on $i_{\text {th }}$ criterion for the $k_{\text {th }}$ supplier. Take $r_{i j}^{k}$ into formula (2), and 
then $R^{\prime}$ can be rewritten as

$$
R=\left[\begin{array}{cccc}
r_{11} & r_{12} & \cdots & r_{1 m} \\
r_{21} & r_{22} & \cdots & r_{2 m} \\
\vdots & \vdots & \vdots & \vdots \\
r_{n 1} & r_{n 2} & \cdots & r_{n m}
\end{array}\right] .
$$

Here $R$ denotes the fuzzy judgment matrix.

4.5. Calculate the Weight of Each Criterion. Grey relational analysis proposed by Deng [7] is used to calculate the weight of each criterion, which is a helpful tool in MCDM problems. Here $a_{i}$ denotes the weight of $i_{\text {th }}$ criterion and $\sum_{i=1}^{n} a_{i}=1, A$ denotes the weight set, and $A=\left(a_{1}, a_{2}, \ldots, a_{n}\right)$. Take the main criteria weights calculation as an example; follow 5 steps [39].

Step 1. Determine the criteria set of importance. For $C=$ $\left\{C_{1}, C_{2}, C_{3}, C_{4}\right\}$, we can construct the matrix

$$
U=\left[\begin{array}{llll}
\lambda_{11} & \lambda_{12} & \cdots & \lambda_{1 m} \\
\lambda_{21} & \lambda_{22} & \cdots & \lambda_{2 m} \\
\lambda_{31} & \lambda_{32} & \cdots & \lambda_{3 m} \\
\lambda_{41} & \lambda_{42} & \cdots & \lambda_{4 m}
\end{array}\right]
$$

and here $\lambda_{i j}(1 \leq i \leq 4,1 \leq j \leq m)$ means the importance level $j$ and $m$ means the number of importance levels.

Step 2. Determine the reference sequence. The reference sequence is determined through scoring the criteria's importance by experts. $U_{0}=\left\{\lambda_{\max 1}, \lambda_{\max 2}, \ldots, \lambda_{\max m}\right\}$ denotes the reference sequence. Here $\lambda_{\max i}=\max \left(\lambda_{i j}\right)(j=$ $1, \ldots, m)$. For the 4 main criteria, we can use $U_{0}=$ $\left\{\lambda_{\max 1}, \lambda_{\max 2}, \ldots, \lambda_{\max m}\right\}$ as the reference sequence and $U_{1}=\left\{\lambda_{11}, \lambda_{12}, \ldots, \lambda_{1 m}\right\}, U_{2}=\left\{\lambda_{21}, \lambda_{22}, \ldots, \lambda_{2 m}\right\}, U_{3}=$ $\left\{\lambda_{31}, \lambda_{32}, \ldots, \lambda_{3 m}\right\}$, and $U_{4}=\left\{\lambda_{41}, \lambda_{42}, \ldots, \lambda_{4 m}\right\}$ as comparative sequences.

Step 3. Calculate the grey relational coefficient. The grey relational coefficient $\xi_{i}(k)$ between the reference sequence $U_{0}$ and the comparative sequence $U_{i}(i=1, \ldots, n)$ can be calculated by

$$
\begin{aligned}
& \xi_{i}(k) \\
& =\frac{\min _{i} \min _{k}\left|U_{0}(k)-U_{i}(k)\right|+\rho \max _{i} \max _{k}\left|U_{0}(k)-U_{i}(k)\right|}{\left|U_{0}(k)-U_{i}(k)\right|+\rho \max _{i} \max _{k}\left|U_{0}(k)-U_{i}(k)\right|} .
\end{aligned}
$$

Here, $k=1, \ldots, m . \rho$ is the distinguishing coefficient and $\rho \in[0,1]$. The purpose of distinguishing coefficient is to reduce the effects of calculation from extremum value. In general, $\rho=0.5$.

Step 4. Calculate the grey relational grade. The grey relational grade directly reflects the pros and cons of the comparative sequence to the reference sequence and can be calculated by

$$
r_{i}=\frac{1}{m} \sum_{k=1}^{m} \xi_{i}(k) .
$$

Step 5. Calculate the weights of criteria. Through formula (8), we can get the weights of criteria:

$$
a_{i}=\frac{r_{i}}{\sum_{i=1}^{m} r_{i}} \quad i=1,2, \ldots, n
$$

For the weights of the 4 main criteria, we can get $A=\left(a_{1}, a_{2}, a_{3}, a_{4}\right)=\left(r_{1} / \sum r_{i}, r_{2} / \sum r_{i}, r_{3} / \sum r_{i}, r_{4} / \sum r_{i}\right)$. In the same manner, we can get the weights of the subcriteria; namely $A_{1}=\left(a_{11}, a_{12}, a_{13}, a_{14}, a_{15}, a_{16}, a_{17}\right), A_{2}=$ $\left(a_{21}, a_{22}, a_{23}, a_{24}\right), A_{3}=\left(a_{31}, a_{32}, a_{33}, a_{34}, a_{35}\right)$, and $A_{4}=$ $\left(a_{41}, a_{42}, a_{43}, a_{44}, a_{45}, a_{46}\right)$.

4.6. Conduct Multistage Fuzzy Comprehensive Evaluation. Formula (9) can be used to conduct multistage fuzzy comprehensive evaluation:

$$
\begin{aligned}
B & =A \cdot R=\left(a_{1}, a_{2}, \ldots, a_{n}\right) \cdot\left[\begin{array}{cccc}
r_{11} & r_{12} & \cdots & r_{1 m} \\
r_{21} & r_{22} & \cdots & r_{2 m} \\
\vdots & \vdots & \vdots & \vdots \\
r_{n 1} & r_{n 2} & \cdots & r_{n m}
\end{array}\right] \\
& =\left(b_{1}, b_{2}, \ldots, b_{m}\right) .
\end{aligned}
$$

Compare the objects' evaluation results and rank them, that is, to convert the comprehensive evaluation results $B$ into comprehensive grades and then select the best green supplier.

\section{Case Study}

5.1. Case Company Background. Company Z, founded in September, 2001, is a steel enterprise located in Changzhou, a city of Jiangsu Province in China. Now company $Z$ has developed into a large-scale steel joint venture with annual steel production capacity of 11.8 million ton, which covers various industries of steel. $\mathrm{Z}$ has been certified by the ISO9001 Quality System Certification, the API-Q1 Quality System Certification of American association of Pipe, the ISO14000 Environment Management System Certification, and so forth.

For company Z, one of the important issues is how to reduce its carbon emissions to maintain market competitiveness and profit. In China, the government has set the target of carbon emissions reduction for the steel enterprises. If the steel enterprise's total carbon emissions exceed the carbon emissions limit set by the government, it needs to buy carbon emissions rights from the carbon emissions trading center; otherwise it will face huge fines from government agencies. Under this condition, company $\mathrm{Z}$ needs to select its green supplier from a large number of suppliers in the low-carbon supply chain.

It is difficult for company $\mathrm{Z}$ to select its best green supplier from these potential suppliers. Firstly, although company $\mathrm{Z}$ has established the criteria for supplier selection, it did not establish the criteria for the green supplier selection in low-carbon supply chain. It is not appropriate to use the existing criteria to select green supplier. Secondly, company $\mathrm{Z}$ has to nondimensionalize the criteria in company $\mathrm{Z}$ 's 
TABLE 2: The evaluated values of 12 main suppliers.

\begin{tabular}{lcccc}
\hline Supplier & $\begin{array}{c}\text { Enterprise low-carbon } \\
\text { qualification } C_{1}\end{array}$ & $\begin{array}{c}\text { Low-carbon production and } \\
\text { service } C_{2}\end{array}$ & $\begin{array}{c}\text { Low-carbon business } \\
\text { operation } C_{3}\end{array}$ & $\begin{array}{c}\text { Low-carbon innovation } C_{4} \\
\text { Supplier A }\end{array}$ S $_{\text {Supplier B }}$ \\
Supplier C & 7.3 & 8.2 & 8.0 & 7.0 \\
Supplier D & 8.6 & 8.7 & 8.3 & 7.2 \\
Supplier E & 8.4 & 8.1 & 7.4 & 7.7 \\
Supplier F & 8.0 & 8.6 & 8.4 & 7.4 \\
Supplier G & 9.0 & 8.7 & 7.8 & 8.2 \\
Supplier H & 9.3 & 8.3 & 8.4 & 8.2 \\
Supplier I & 7.6 & 8.2 & 8.4 & 8.3 \\
Supplier K & 9.2 & 8.0 & 8.3 & 8.0 \\
Supplier J & 8.4 & 8.3 & 8.0 & 8.3 \\
Supplier M & 8.8 & 8.7 & 7.6 & 7.9 \\
\hline
\end{tabular}

TABLE 3: The importance of the 4 main criteria.

\begin{tabular}{ccccccccccc}
\hline & Expert 1 & Expert 2 & Expert 3 & Expert 4 & Expert 5 & Expert 6 & Expert 7 & Expert 8 & Expert 9 & Expert 10 \\
\hline$C_{1}$ & 10 & 9 & 10 & 8 & 9 & 8 & 8 & 7 & 8 & 9 \\
$C_{2}$ & 8 & 8 & 10 & 8 & 9 & 9 & 6 & 6 & 7 & 7 \\
$C_{3}$ & 8 & 9 & 10 & 9 & 9 & 10 & 9 & 10 & 8 & 8 \\
$C_{4}$ & 6 & 7 & 10 & 7 & 7 & 7 & 8 & 6 & 7 & 8 \\
\hline
\end{tabular}

previous supplier selection, which brings a lot of calculating work. Moreover, it is difficult for company $\mathrm{Z}$ to deal with qualitative criteria. Thirdly, the managers and practitioners' understanding of the weights of criteria for green supplier selection are in the grey state, so it is suitable to use grey relational analysis to calculate the criteria's weights. Fourthly, company $\mathrm{Z}$ usually used expert scoring method to select its suppliers, which is very subjective and is easily influenced by other factors. Therefore, company $\mathrm{Z}$ urgently needs an approach to select its green supplier in low-carbon supply chain management.

5.2. Application of the Proposed Criteria and Method. After referring to a preliminary list of criteria compiled using literature review on green supplier selection and the company Z's actual situation, 10 managers, practitioners, and experts are asked to determine the green supplier selection criteria and allowed to discuss each criterion for clarification. Finally, it can be seen in Table 1 that the main criteria for company Z's green supplier selection are grouped into four categories, which also include 22 subcriteria.

For company $\mathrm{Z}$, it has a large number of suppliers. Taking the business development and needs to reduce carbon emissions into account, company $\mathrm{Z}$ only needs to select its green supplier from 12 main suppliers. The method proposed in Section 4 is used for green supplier selection. For the sake of simplicity, we only give out the calculation for the 4 main criteria. The evaluated values of 12 main suppliers, which are given by 10 managers, practitioners, and experts, are listed in Table 2.

From Table 2, the mean value and standard deviation of the 4 main criteria are $\bar{x}=(8.5083,8.3167,8.0583,7.8833)$ and $s=(0.5334,0.2980,0.4461,0.4569)$, respectively, through calculation. Take $\bar{x}$ and $s$ into formula (1), and then $z_{i}$ can be obtained. Next, take $z_{i}$ into formula (2), and then the fuzzy judgment matrix $R$ also can be obtained. In the same way, for the sake of simplicity, we give out the fuzzy judgment matrix which only includes supplier A, supplier B, supplier C, supplier D, and supplier E. So $R$ can be written as

$$
R=\left[\begin{array}{llll}
0.3480 & 0.3477 & 0.4480 & 0.0266 \\
0.0921 & 0.9009 & 0.0446 & 0.0674 \\
0.5682 & 0.2336 & 0.8877 & 0.8191 \\
0.4195 & 0.8292 & 0.0700 & 0.3441 \\
0.1703 & 0.9009 & 0.7781 & 0.1451
\end{array}\right] .
$$

The importance of the 4 main criteria determined by 10 managers, practitioners, and experts is listed in Table 3.

From Table 3, we can get the reference sequence and the comparative sequences: $U_{o}=\{10,9,10,9,9,10,9,10,8,9\}$, $U_{1}=\{10,9,10,8,9,8,8,7,8,9\}, U_{2}=\{8,8,10,8,9,9,6,6$, $7,7\}, U_{3}=\{8,9,10,9,9,10,9,10,8,8\}$, and $U_{4}=\{6,7,10,7$, $7,7,8,6,7,8\}$.

According to formulas (6) and (7), the grey relational grade of 4 main criteria are, respectively, $r_{1}=0.8233, r_{2}=$ $0.6400, r_{3}=0.9167$, and $r_{4}=0.5567$. Here $\rho=0.5$. By 
formula (8), we can get the weights of the 4 main criteria $A=(0.2804,0.2179,0.3121,0.1891)$.

In the end, we can conduct the fuzzy comprehensive evaluation by formula (9): $B=A \cdot R=(0.3182,0.2488$, $0.6426,0.3854,0.5145)$. So the order of green supplier selection is as follows: supplier C, supplier E, supplier D, supplier A, and supplier B.

Based on the evaluation and selection above, supplier $\mathrm{C}$ is recommended as company Z's best green supplier. In fact, company $\mathrm{Z}$ has given priority to supplier $\mathrm{C}$ in its new projects construction according to the results. Supplier E is recommended as the reserved green supplier.

Through the analysis above, it is easy to see the advantages and disadvantages of the alternative green suppliers and the field and direction that 12 suppliers need to improve. Based on the concept of continuous improvement, company $\mathrm{Z}$ can continue to improve its competitiveness and profitability in low-carbon supply chain.

\section{Conclusions}

With "United Nations Framework Convention on Climate Change" and "Kyoto Protocol" signed and entering into force, there has been broad consensus on carbon emissions reduction. So low-carbon supply chain management has become an inevitable choice for enterprises to cope with the pressure from the government and the market. It is one of the most important factors to select green supplier for the success of low-carbon supply chain.

In this paper, we propose a fuzzy-grey multicriteria decision making approach for green supplier selection in lowcarbon supply chain. According to the demand of enterprises in low-carbon supply chain, 4 main criteria and 22 subcriteria are established for green supplier selection. A method integrating fuzzy set theory and grey relational analysis is also proposed. According to the principle that the criteria value will obey normal distribution in the case of large sample size, a membership function of normal distribution is also introduced to calculate the membership degree of each criterion. Due to that the people's understanding of the weights of criteria for green supplier selection is in the grey state, so grey relational analysis is used to calculate the weight of each criterion. Fuzzy comprehensive evaluation is also used due to the nature of unquantifiable and incomplete information in green supplier selection. The proposed method can make the localization of individual green supplier more objectively and more accurately in the same trade, and it is easier for us to find the problems in green supplier selection. A steel company $\mathrm{Z}$ is studied to verify the scientificity and feasibility of the proposed criteria and method for green supplier selection. The result shows that the proposed criteria and method have good applicability in practical situation. To some extent, the proposed method can be widely used as a structural model for green supplier selection.

It needs to be pointed out that the approach proposed in this paper is not suitable for green supplier selection when there are only a small number of potential suppliers or criteria. For further study, a fuzzy based questionnaire can be used for data collection in order to prevent information bias.

\section{Conflicts of Interest}

The authors declare that there are no conflicts of interest regarding the publication of this paper.

\section{Acknowledgments}

This research was supported by the Fundamental Research Funds for the Central Universities (nos. 2015B24014 and 2017B43314).

\section{References}

[1] Trucost, Carbon emissions-measuring the risks, 2009, Available from: http://www.nsf.org/business/sustainability/SUS_NSF_Trucost_Report.pdf.

[2] H. S. Kilic, "An integrated approach for supplier selection in multi-item/multi-supplier environment," Applied Mathematical Modelling, vol. 37, no. 14-15, pp. 7752-7763, 2013.

[3] B. Kang, Y. Hu, Y. Deng, and D. Zhou, "A new methodology of multicriteria decision-making in supplier selection based on $Z$-numbers," Mathematical Problems in Engineering, vol. 2016, Article ID 8475987, 17 pages, 2016.

[4] A. Awasthi and G. Kannan, "Green supplier development program selection using NGT and VIKOR under fuzzy environment," Computers and Industrial Engineering, vol. 91, pp. 100108, 2016.

[5] D. Kannan, R. Khodaverdi, L. Olfat, A. Jafarian, and A. Diabat, "Integrated fuzzy multi criteria decision making method and multi-objective programming approach for supplier selection and order allocation in a green supply chain," Journal of Cleaner Production, vol. 47, pp. 355-367, 2013.

[6] S. Hamdan and A. Cheaitou, "Supplier selection and order allocation with green criteria: an MCDM and multi-objective optimization approach," Computers \& Operations Research, vol. 81, pp. 282-304, 2017.

[7] J. L. Deng, "Introduction to grey system theory," The Journal of Grey System, vol. 1, no. 1, pp. 1-24, 1989.

[8] K. Govindan, S. Rajendran, J. Sarkis, and P. Murugesan, "Multi criteria decision making approaches for green supplier evaluation and selection: a literature review," Journal of Cleaner Production, 2013.

[9] M. Igarashi, L. De Boer, and A. M. Fet, "What is required for greener supplier selection? A literature review and conceptual model development," Journal of Purchasing and Supply Management, vol. 19, no. 4, pp. 247-263, 2013.

[10] W. Ho, X. Xu, and P. K. Dey, "Multi-criteria decision making approaches for supplier evaluation and selection: a literature review," European Journal of Operational Research, vol. 202, no. 1, pp. 16-24, 2010.

[11] L. de Boer, E. Labro, and P. Morlacchi, "A review of methods supporting supplier selection," European Journal of Purchasing and Supply Management, vol. 7, no. 2, pp. 75-89, 2001.

[12] C. Wu and D. Barnes, "A literature review of decision-making models and approaches for partner selection in agile supply chains," Journal of Purchasing and Supply Management, vol. 17, no. 3, pp. 256-274, 2011. 
[13] J. Chai, J. N. K. Liu, and E. W. T. Ngai, "Application of decisionmaking techniques in supplier selection: a systematic review of literature," Expert Systems with Applications, vol. 40, no. 10, pp. 3872-3885, 2013.

[14] K. Shaw, R. Shankar, S. S. Yadav, and L. S. Thakur, "Supplier selection using fuzzy AHP and fuzzy multi-objective linear programming for developing low carbon supply chain," Expert Systems with Applications, vol. 39, no. 9, pp. 8182-8192, 2012.

[15] K. Shaw, M. Irfan, R. Shankar, and S. S. Yadav, "Low carbon chance constrained supply chain network design problem: a benders decomposition based approach," Computers and Industrial Engineering, vol. 98, pp. 483-497, 2016.

[16] M. Nakajima, A. Kimura, and B. Wagner, "Introduction of material flow cost accounting (MFCA) to the supply chain: a questionnaire study on the challenges of constructing a lowcarbon supply chain to promote resource efficiency," Journal of Cleaner Production, vol. 108, no. 3, pp. 1302-1309, 2015.

[17] Q. P. Wang, D. Z. Zhao, and L. F. He, "Contracting emission reduction for supply chains considering market low-carbon preference," Journal of Cleaner Production, vol. 120, no. 10, pp. 72-84, 2016.

[18] Y. Zhou, M. Bao, X. Chen, and X. Xu, "Co-op advertising and emission reduction cost sharing contracts and coordination in low-carbon supply chain based on fairness concerns," Journal of Cleaner Production, vol. 133, no. 11, pp. 402-413, 2016.

[19] Z. F. Mao, S. Zhang, and X. M. Li, "Low carbon supply chain firm integration and firm performance in China," Journal of Cleaner Production, vol. 133, no. 10, pp. 1-8, 2016.

[20] Z. Chen and W. Yang, "An MAGDM based on constrained FAHP and FTOPSIS and its application to supplier selection," Mathematical and Computer Modelling, vol. 54, no. 11-12, pp. 2802-2815, 2011.

[21] J. Lee, H. Cho, and Y. S. Kim, "Assessing business impacts of agility criterion and order allocation strategy in multi-criteria supplier selection," Expert Systems with Applications, vol. 42, no. 3, pp. 1136-1148, 2015.

[22] H. M. Wang Chen, S.-Y. Chou, Q. D. Luu, and T. H.-K. Yu, "A fuzzy MCDM approach for green supplier selection from the economic and environmental aspects," Mathematical Problems in Engineering, vol. 2016, Article ID 8097386, 10 pages, 2016.

[23] A. H. I. Lee, H. Kang, C. F. Hsu, and H. Hung, "A green supplier selection model for high-tech industry," Expert Systems with Applications, vol. 36, no. 4, pp. 7917-7927, 2009.

[24] M.-L. Tseng, "Green supply chain management with linguistic preferences and incomplete information," Applied Soft Computing Journal, vol. 11, no. 8, pp. 4894-4903, 2011.

[25] C.-W. Hsu, T.-C. Kuo, S.-H. Chen, and A. H. Hu, "Using DEMATEL to develop a carbon management model of supplier selection in green supply chain management," Journal of Cleaner Production, vol. 56, no. 9, pp. 164-172, 2013.

[26] O. Gurel, A. Z. Acar, I. Onden, and I. Gumus, "Determinants of the green supplier selection," Procedia-Social and Behavioral Sciences, vol. 181, pp. 131-139, 2015.

[27] I. Dobos and G. Vörösmarty, "Green supplier selection and evaluation using DEA-type composite indicators," International Journal of Production Economics, vol. 157, no. 1, pp. 273-278, 2014.

[28] A. Awasthi, S. S. Chauhan, and S. K. Goyal, "A fuzzy multicriteria approach for evaluating environmental performance of suppliers," International Journal of Production Economics, vol. 126, no. 2, pp. 370-378, 2010.
[29] R. G. Masoud, C. Ali, S. Amin, and M. Ashkan, "Prioritizing green supplier selection criteria using fuzzy analytical network process," Procedia CIRP, vol. 26, no. 10, pp. 689-694, 2015.

[30] L.-h. Li, J.-c. Hang, Y. Gao, and C.-y. Mu, "Using an integrated group decision method based on SVM, TFN-RS-AHP, and TOPSIS-CD for cloud service supplier selection," Mathematical Problems in Engineering, vol. 2017, Article ID 3143502, 14 pages, 2017.

[31] B. Pardha Saradhi, N. Ravi Shankar, and C. Suryanarayana, "Novel distance measure in fuzzy TOPSIS for supply chain strategy based supplier selection," Mathematical Problems in Engineering, vol. 2016, Article ID 7183407, 17 pages, 2016.

[32] A. Amindoust, S. Ahmed, A. Saghafinia, and A. Bahreininejad, "Sustainable supplier selection: a ranking model based on fuzzy inference system," Applied Soft Computing Journal, vol. 12, no. 6, pp. 1668-1677, 2012.

[33] S. Darabi and J. Heydari, "An interval- valued hesitant fuzzy ranking method based on group decision analysis for green supplier selection," IFAC-Papers OnLine, vol. 49, no. 2, pp. 12-17, 2016.

[34] R. J. Kuo, Y. C. Wang, and F. C. Tien, "Integration of artificial neural network and MADA methods for green supplier selection," Journal of Cleaner Production, vol. 18, no. 12, pp. 1161-1170, 2010.

[35] E. E. Karsak and M. Dursun, "An integrated fuzzy MCDM approach for supplier evaluation and selection," Computers and Industrial Engineering, vol. 82, no. 9, pp. 82-93, 2015.

[36] T. Yamada, Y. Yoshizaki, N. Itsubo, and M. Inoue, "Low-carbon and economic supplier selection using life cycle inventory database by Asian international input-output tables," Procedia CIRP, vol. 26, no. 6, pp. 317-322, 2015.

[37] M. Yazdani, P. Chatterjee, E. K. Zavadskas, and S. Hashemkhani Zolfani, "Integrated QFD-MCDM framework for green supplier selection," Journal of Cleaner Production, vol. 142, no. 2, pp. 3728-3740, 2017.

[38] N. Banaeian, H. Mobli, B. Fahimnia, I. E. Nielsen, and M. Omid, "Green supplier selection using fuzzy group decision making methods: a case study from the agric-food industry," Computers \& Operations Research, vol. 80, no. 3, pp. 178-188, 2015.

[39] C. Q. Zhang and W. P. Hu, "Application of Gray-AHP in denigration technology evaluation," Environmental Engineering, vol. 28, no. 4, pp. 97-99, 2010. 


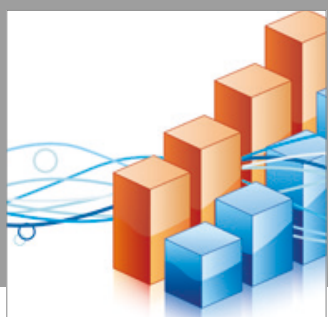

Advances in

Operations Research

vatersals

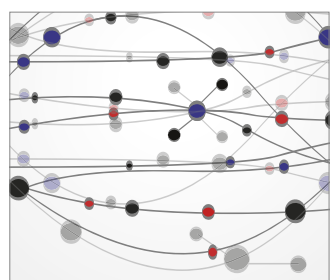

\section{The Scientific} World Journal
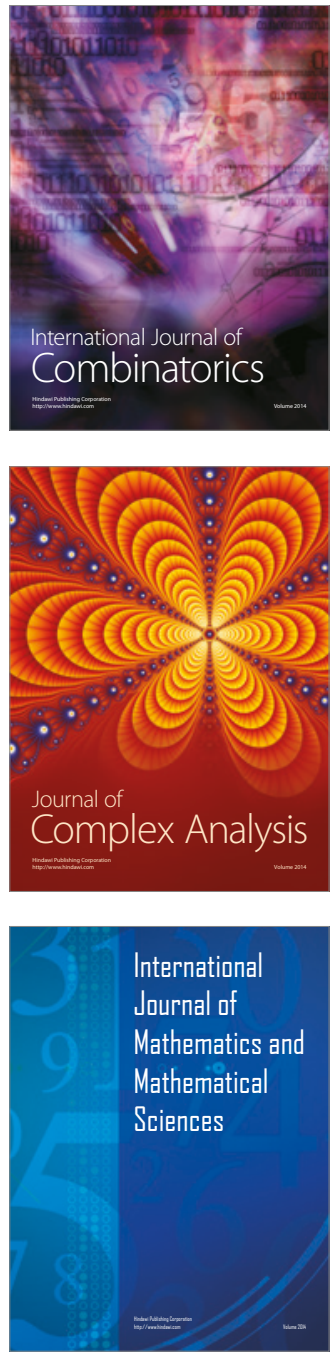
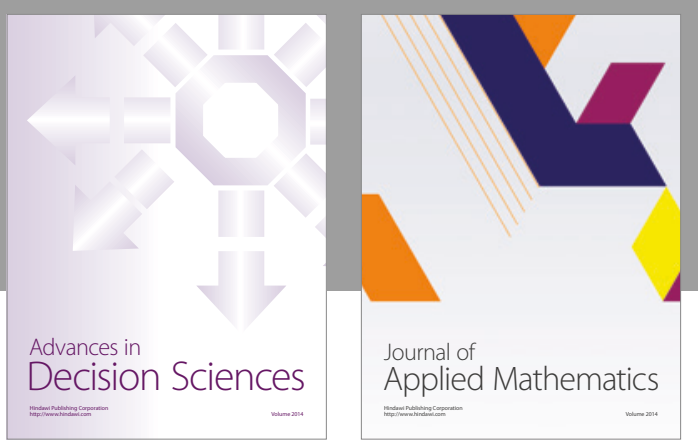

Algebra

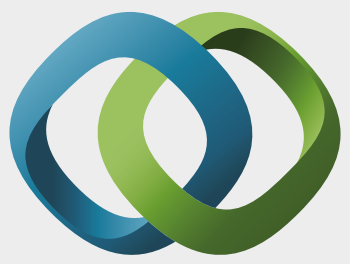

\section{Hindawi}

Submit your manuscripts at

https://www.hindawi.com
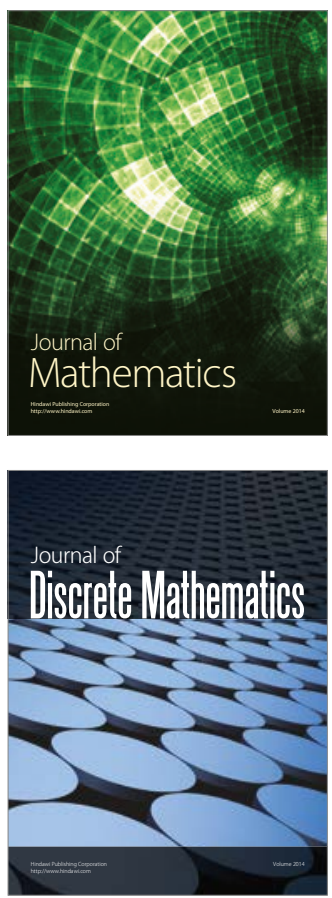

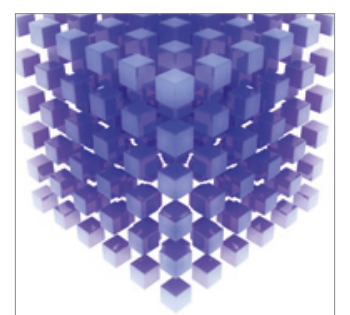

Mathematical Problems in Engineering
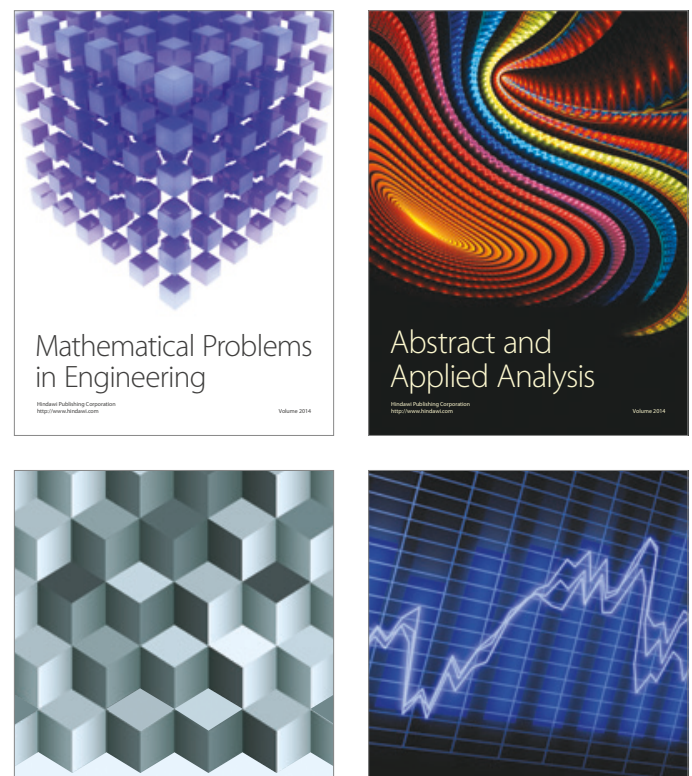

Journal of

Function Spaces

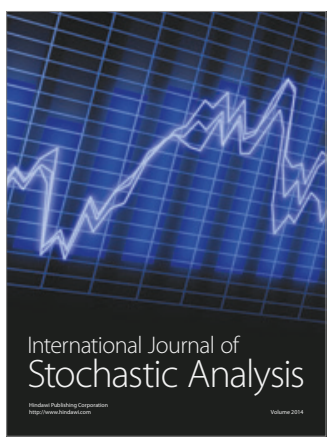

Probability and Statistics
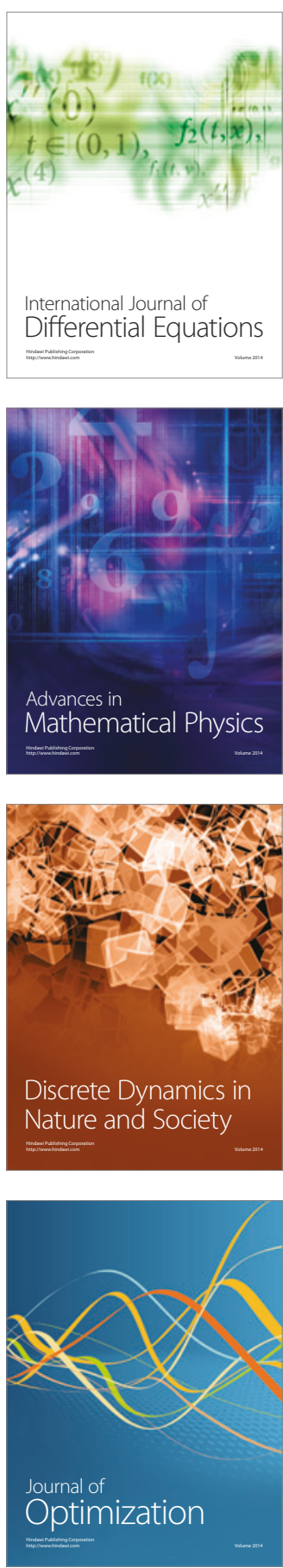